\title{
Analysis of Technical Energy Conservation Potential of China's Energy Consumption Sectors
}

\author{
Xi Yang1,2, Qing Tong1, Xunmin Ou ${ }^{1,2 *}$ \\ ${ }^{1}$ Institute of Energy, Environment and Economy, Tsinghua University, Beijing, China \\ ${ }^{2}$ China Automotive Energy Research Center, Tsinghua University, Beijing, China \\ Email: ouxm@tsinghua.edu.cn
}

Received 10 September 2014; revised 10 October 2014; accepted 19 October 2014

Copyright (C) 2014 by authors and Scientific Research Publishing Inc.

This work is licensed under the Creative Commons Attribution International License (CC BY). http://creativecommons.org/licenses/by/4.0/

cc) (i) Open Access

\begin{abstract}
It is necessary for China to refocus its energy conservation effort from the industrial sector (field) to all three sectors simultaneously, i.e. industry, construction and transport. In addition, it should also make significant effort for conserving energy on general technical equipment that are used in large quantities and for a variety of applications. Therefore, there is a need to integrate industrial, construction and transport sectors, i.e. the integration between key technologies and widely used technologies, between hard and soft management, between energy-saving technologies and comprehensive resource utilization technologies. According to estimates, if China's energy consuming sectors adopted appropriate energy-saving technologies, total energy-savings (using 2010 as the baseline) would be 200 million, 450 million, 650 million and 800 million tons of standard coal in 2015, 2020, 2025 and 2030, respectively.
\end{abstract}

\section{Keywords}

Energy Conservation, Technology Energy-Saving, Policy Analysis, China

\section{Introduction}

"Energy Reduction Revolution” is mainly realized via the following two approaches: by reducing the consumption of energy by services and improving energy utilization efficiency (i.e. using less energy for a similar output). The latter is generally called technical energy conservation, i.e. continuously improving energy utilization efficiency of existing and new energy facilities (or equipment), and reducing the energy consumption per unit out-

${ }^{*}$ Corresponding author. 
put of energy services. Technical energy conservation is further divided into progressive and fundamental types. Thus, in addition to gradual increase of energy efficiency through incremental innovation of the main technologies in service, additional exploration of fundamental technological innovations should be undertaken to achieve breakthroughs in energy efficiency.

\section{Estimation of Technical Energy Conservation Potential by Sector}

Energy conservation applies to every sector of the national economy and social life, and can be realized through a variety of approaches and measures. As for the methodology, prioritizing key fields and promoting effective measures can accomplish the greatest performance. Key energy conservation sectors must adhere to the idea of "doing two jobs at once"; that is, paying attention to areas consuming high amounts of energy, and to general technical equipment that are commonly used in large quantities. In the past, all energy conservation work revolved around the industrial sector as it had the highest energy consumption. However, in the future, the energy conservation potential of the industrial sector will wane, and will shift to the consumption structure of people "living" and "traveling". The energy consumption in residential \& commercial real estate and the transport \& logistics sectors will grow rapidly (Figure 1) [1] [2]. Therefore, it is necessary to refocus energy conservation from the industrial sector (field) to all three sectors, i.e. industry, construction and transport, and to increase the energy conserving effort from general technical equipment that are used in large quantities and for a variety of applications.

Special attention should be paid to the industrial, construction (including tertiary industries and household consumption) and transport sectors - the main energy consuming sectors of China (Table 1). Industrial energy usage accounts for over $70 \%$ of China's energy consumption; thus it is a key sector for energy conservation. In addition, accelerated urbanization and motorization has led to a rapid growth in energy consumption within China's construction and transport sectors.

Standards for energy conservation are set for the purpose of energy saving, and used as the fundamental basis to control energy consumption from source. Hence, energy conservation should be considered as a focus of China's energy policies, and relevant industrial standards, rules and regulations related to energy conservation should constantly be developed and improved.

\subsection{Industrial Sector}

Though the industrial sector saw great accomplishments in energy conservation, a number of issues still need to be addressed: energy efficiency needs to be improved, the promotion of energy-saving technologies and equipment is not sufficient, supporting regulations and system standards have to be perfected and so on. Currently, there is a gap in energy consumption per unit output value and per unit production between the Chinese industrial sector and that of developed countries. Thus, there is considerable energy conservation potential.

The comparison between the unit energy consumption of the main energy-intensive products between China

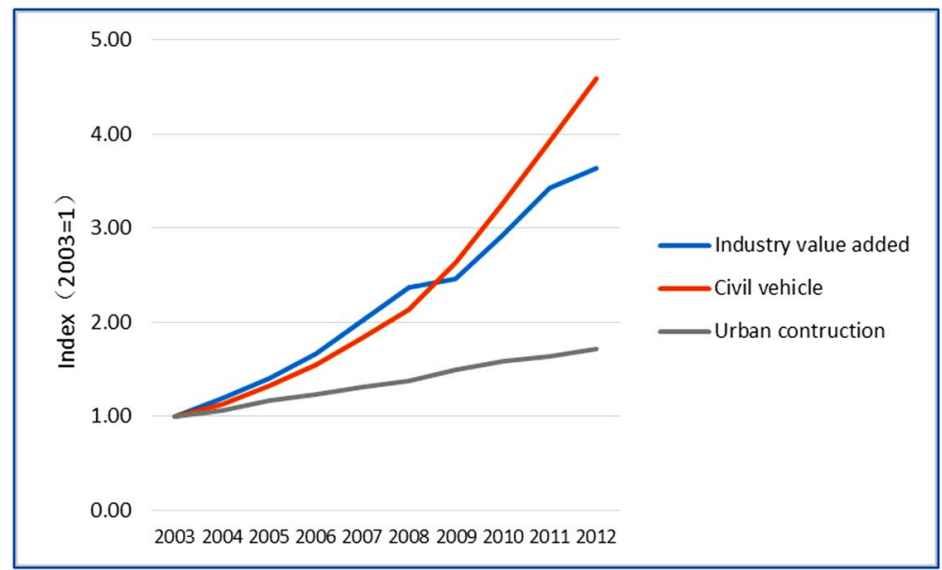

Figure 1. Growth of industrial, value-added civil vehicle and urban building area in China (2003-2012). 
Table 1. Proportion of final energy consumption by sector ${ }^{\mathrm{a}}(\%)$.

\begin{tabular}{|c|c|c|c|}
\hline Sector & 2005 & 2010 & 2011 \\
\hline Primary industry & 2.6 & 2.0 & 1.9 \\
\hline Industrial sector & 71.5 & 71.1 & 70.8 \\
\hline Construction & 1.4 & 1.9 & 1.7 \\
\hline Transport & 7.8 & 8.0 & 8.2 \\
\hline Wholesale, retail, accommodation, and catering sectors & 2.1 & 2.1 & 2.2 \\
\hline Other industries & 3.9 & 4.2 & 4.4 \\
\hline Household consumption & 10.7 & 10.6 & 10.7 \\
\hline
\end{tabular}

${ }^{\mathrm{a}}$ Data Source: Yearbook of Energy Statistical Records. According to internationally accepted statistical standards. The energy consumption in transport includes both operational transport and transport in other sectors; China Energy Research Society quoted IEA data in the Annual Report on China's Energy Development (2013), and said that in 2010 energy consumption in China's transport sector accounted for $12.1 \%$ of final energy consumption, which is below the global average of $23.9 \%$; Construction energy consumption is the energy consumed in non-production construction, i.e. in civil construction (residential and commercial buildings).

and foreign countries shows that the energy efficiency of some industrial sectors of China still needs improvement. The emphasis should be on technology development and their application, where required. For instance, as described in the appendix of China Energy Statistics Yearbook (2013), energy consumption per ton of steel, comprehensive energy consumption per ton of cement, and per ton of paper and paperboard in China is $10 \%$ $40 \%$ higher than Japan. China uses naphtha and coal as the main raw material to produce ethylene and synthesize ammonia, respectively. Thus the corresponding overall energy consumption is about $50 \%$ higher than the international advanced level (the Middle East uses ethane to produce ethylene, and USA uses natural gas to synthesize ammonia).

In terms of standards, it is necessary to accelerate the formulation (revision) of standards for limited energy consumption per unit product (process); increase the implementation of energy efficiency standards in industrial equipment, household appliances and lighting, information and communications and other fields; encourage the development of stringent local standards for unit consumption and energy efficiency; promote international coordination and unification of energy conservation standards for industry; strengthen the certification of energysaving products and the establishment of inspection capability; expand the scope of energy efficiency labeling of energy-saving products and increase government procurement of energy-saving products.

The Institute of Energy, Environment and Economy, Tsinghua University, concluded that the amount of energysaving over, a fixed period within each five-year plan period from 2010-2025, will be approximately 100 million tons of standard coal following the implementation of key industrial energy-saving technologies.

\subsection{Construction Sector}

Energy saving in construction refers to energy conservation and consumption reduction during the entire life cycle of buildings. Due to limited statistical standards and methods, no comprehensive energy consumption data of the entire building sector is available in China at the moment. Relevant studies suggest that the energy consumption of buildings makes up about $20 \%$ of total energy consumption across China. Buildings are the main source of energy consumption within the tertiary industry, wholesale and retail, accommodation and catering sectors and two other main industries as well as households. The Building Energy Research Centre, Tsinghua University, estimated that the current total energy consumption in building operations is approximately 680 million tons of standard coal in China. However, with future increases in construction the energy consumption in buildings can still be controlled at 840 million tons of standard coal by adopting a series of technologies, standards and management measures.

China has achieved remarkable results in energy saving in buildings; however, some problems still need to be addressed. These include, unbalanced progress of energy conservation in different regions; differing construction stages and types; lack of scientific guidance to select energy-saving technologies; technical difficulties in saving energy in buildings as per local conditions; inadequate incentives and restrictions; insufficient awareness of energy-saving within enterprises and individuals; poor basic information about energy-saving strategies in building, amongst other areas. 
Over the past decade, a number of energy-saving technologies have been widely applied in new and renovated energy-saving buildings, with most showing improved results. In the future a number of increasingly competitive technologies with improved energy conservation potential and emission reduction must be promoted. If energy-saving and emission reduction measures are effectively implemented, approximately 70 - 80 million tons of standard coal equivalents can be saved, over each five-year plan period from 2010-2020, within the building sector.

There is no uniform implementation of energy conservation standards for new buildings. On the whole, the energy-saving standards promulgated for the building sector, during the 11th Five-Year Plan, were 50\% of the consumption level between 1980-1981 (the 50\%-standard), which was gradually increased to 65\% at the end of the 11th Five-Year Plan. This indicates low levels of energy efficiency standards.

\subsection{Transportation Sector}

The existing statistical system of China, which contains the energy consumption statistics for the communication and transportation sectors, only includes enterprises engaged in social operations. The system does not include data for the energy consumption of industrial enterprises, privately owned vehicles of enterprises and public units, and private cars. As per general international standards it is estimated that the actual energy consumption of China's transportation sector is far more than current statistics. Research estimates that China's transportation sector accounts for $10 \%$ to $15 \%$ of the total national energy consumption. Experience from developed countries suggests that on entering a steady state of urbanization, communication and transportation will reach $30 \%$ to $40 \%$ of the country's total energy consumption.

The transportation sector is one of the fastest growing areas of energy consumption. While fully implementing the prioritized developmental strategy of public transport, developing intercity rail network and allowing environmentally friendly travel, China should also try to optimize energy-saving of the transportation infrastructure and utilize energy-saving traffic technologies. Although the country has already achieved preliminary success, the energy saving of communication and transportation is still facing major issues. These include, underdeveloped transportation infrastructure; development of public transport is lagging behind; the lack of optimizing energy-saving management systems for transport; improvement required in traffic energy-saving policy systems; and the existing trend of consumers purchasing large-sized and high-fuel consuming SUV vehicles.

The transportation sector needs to study and develop a special action plan to establish a system of standards for energy-saving and emissions reduction. The sector needs to build standards for fuel consumption in shipping operations, port cargo handling machines and traffic construction machines and set a carbon emissions limit. It also needs to improve technical standards and implement energy-saving designs for highway bridges, engineering and greenery work. Legislation must be improved and energy-saving traffic management systems must be normalized and standardized. Older automobiles, locomotives and ships must be phased-out and automobile fuel quality improved. Finally, set a higher standard limit for fuel economy as found in other parts of the world to control the growth of heavy-emission cars.

A publication, "Research on medium and long-term energy-saving problems for China’s transportation” [3], suggests that large energy-savings of up to 140 MTCE and 310 MTCE in 2020 and 2030, respectively, can potentially be achieved. Amongst this highway transportation and private cars will account for the majority of up to two-thirds. Research undertaken by the China Automotive Energy Research Center (CAERC), Tsinghua University, also drew a similar conclusion [4].

\section{Results of Comprehensive Measurements and Calculations}

Comprehensive measurements and calculations have a huge potential for generalized technology energy saving. The energy savings over fixed periods of each five-year plan, from 2010 to 2030, are shown in Table 2. The industrial sector has some potential in the first 15 years, which gradually reduces. The construction sector has huge energy-saving potential during the first 5 years, which later plateaus. The potential of the transportation sector gradually increases, will peak in 2015-2020, and then gradually drop. After 2010, the energy saving over fixed periods, in China’s energy utilization sectors, increases from 200 MTCE to 250 MTCE, and then gradually reduces. Compared with 2010, the total potential energy saving will keep growing in 2015, 2020, 2025 and 2030 with values of 200, 450, 650 and 800 MTCE, respectively, albeit at a slow growth rate. 
Table 2. Energy saving potential in China’s energy utilization fields (x102MTCE/year).

\begin{tabular}{ccccccc}
\hline & $2010-2015$ & $2015-2020$ & $2020-2025$ & $2025-2030$ & After 2030 \\
\hline Industrial sector & 1 & 1 & 1 & 0.75 & Gradually decreases \\
Construction sector & 0.5 & 0.25 & 0.25 & 0.25 & Plateaus \\
Transportation sector & 0.5 & 1.25 & 0.75 & 0.5 & Gradually decreases \\
Total & 2.0 & 2.5 & 2.0 & 1.5 & Gradually decreases \\
The year-end accumulative potential compared to 2010 & 2.0 & 4.5 & 6.5 & 8.0 & Slowly increases \\
\hline
\end{tabular}

\section{Policy Suggestions}

Thus, an energy saving revolution would need integrations within the three sectors, i.e. industrial, construction and traffic. These include, the integration between key technologies and widely used technologies, between advanced technologies and flexible management, between energy-conservation technologies and comprehensive resource utilization technologies. In addition, promoting energy efficiency standards and introducing regulatory policies are also important tools.

Firstly, utilize advanced energy-saving technologies to gradually make China's industrial energy efficiency reach world-leading levels, and continue to refine mandatory national standards for energy consumption per unit product in key industries. Secondly, implement a green building plan to promote energy efficient building, and improve the level of energy efficiency with the support of regulations, technology, standards and design. Thirdly, promote energy-efficient transportation; speed up the construction of comprehensive transport systems; optimize transportation structure; encourage the use of energy efficient and environmentally friendly vehicles; promote the construction of energy efficient transportation infrastructure; increase investment in research and development of new energy vehicles; scientifically plan the construction of supporting facilities for gas refilling, battery charging, amongst other areas.

\section{References}

[1] National Bureau of Statistics of China (2013) China Statistics Yearbook 2013. China Statistics Press, Beijing.

[2] Building Energy Research Center of Tsinghua University (2013) Annual Report on Construction Energy-Saving Development in China. Building Energy Research Center of Tsinghua University, Beijing.

[3] Fu, Z.H., et al. (2011) Study on the Problems of Long-Term Energy Saving of Communication and Transportation of China. China Communication Press, Beijing.

[4] CAERC (2012) China Automotive Energy Outlook 2012. China Scientific Press, Beijing. 
Scientific Research Publishing (SCIRP) is one of the largest Open Access journal publishers. It is currently publishing more than 200 open access, online, peer-reviewed journals covering a wide range of academic disciplines. SCIRP serves the worldwide academic communities and contributes to the progress and application of science with its publication.

Other selected journals from SCIRP are listed as below. Submit your manuscript to us via either submit@scirp.org or Online Submission Portal.
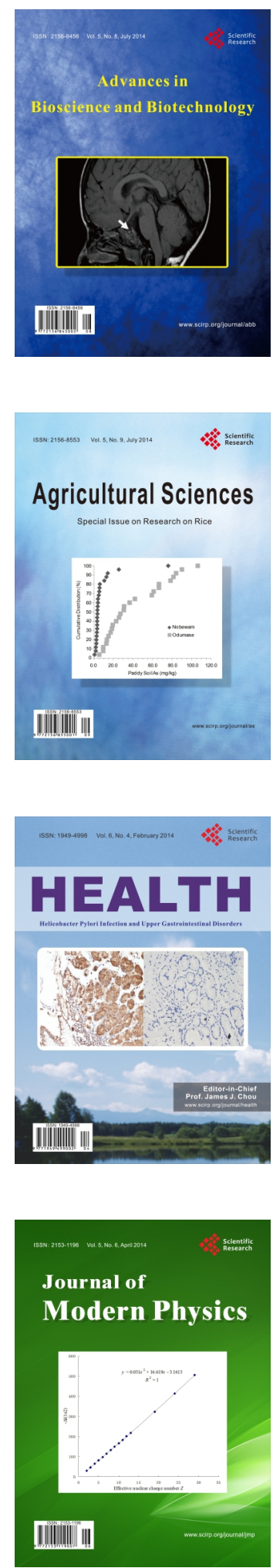
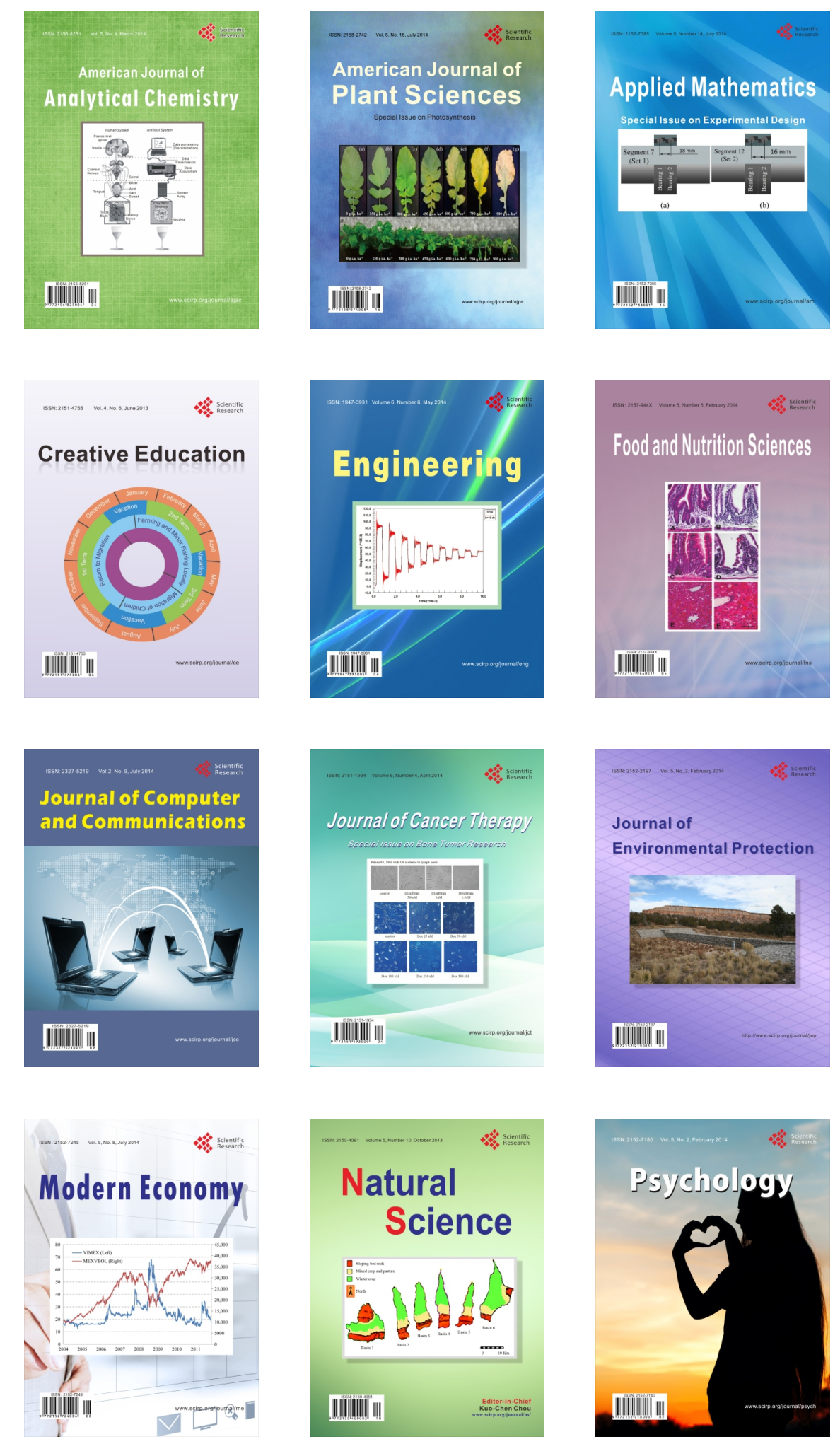